\title{
25th Anniversary of ECAP: the origins of the Journal
}

\author{
Helmut Remschmidt ${ }^{1}$ Philip Graham ${ }^{2}$
}

Published online: 17 January 2017

C) Springer-Verlag Berlin Heidelberg 2017

At the 8th ESCAP congress in Varna/Bulgaria in 1987, Philip Graham, Herman van Engeland (1943-2016), and Helmut Remschmidt discussed the necessity to establish a European Journal of Child and Adolescent Psychiatry. The journals that existed at that time did not seem to provide adequate coverage of the academic literature that could be available from European child and adolescent psychiatrists.

We invited a representative of Hogrefe, a publisher based in Göttingen, to Marburg to the 3rd International Meeting of the WHO/European child psychiatry research group (Oct $1-4,19890)$. We were able to negotiate an outline contract with him to our mutual satisfaction. There was a problem with the title of the Journal because there was already in existence a journal called "Acta Paedopsychiatrica". This was not, in fact specifically European but more broadly international so we were able to overcome this difficulty.

The first issue of the new journal came out in January 1992, Christopher Gillberg was editor-in-chief, co-editors were Herman van Engeland (Netherlands), Elena Garralda (UK), Philip Graham (UK), Helmut Remschmidt (Germany), Hans-Christoph Steinhausen (Switzerland), and Frank Verhulst (Netherlands). Philip Graham acted also as book review editor.

In the editorial to the first issue of ECAP (written in May 1991), the editors stated:

Helmut Remschmidt

remschm@med.uni-marburg.de

1 Department of Child and Adolescent Psychiatry, Philipps-University Marburg, Schützenstraße 49, 35039 Marburg, Germany

2 University College London, Gower Street, WC1EBT, London, UK
"The number of international journals, devoted entirely to child and adolescent psychiatry, is small indeed, and there appears to be room for another journal exclusively covering this area. Europe is now fast becoming a concept with much wider implications than purely descriptively geographic. What better name then for the new journal than European Child and Adolescent Psychiatry?

European Child and Adolescent Psychiatry will aim to promote the growth of empirically based clinical child and adolescent psychiatry throughout Europe (and the rest of the world) by publishing original papers on systematic scientific studies, review articles, annotations, occasional case reports, book (and video) reviews, and items of information. Supplements relevant to the study of child and adolescent psychiatry problems will also appear from time to time. It is expected that most of the published material will have European roots, but the journal welcomes high-quality contributions from all over the world.

The journal will appear quarterly. All papers published will be in English, with summaries in French and German. It will be the official organ of the European Society for Child and Adolescent Psychiatry.

The first issue of the journal includes papers by authors from England, Germany, the Netherlands, Scotland, Sweden, and Switzerland. We hope to attract authors from many other countries so that future issues, too, make up an international journal in the true sense of that word".

Working with Hogrefe Publishers turned out to be complicated and associated with financial problems. So in 1995, Helmut Remschmidt negotiated in the editors' name with Steinkopff Publishers in Darmstadt/Germany, a subsidiary of Springer international, with head offices in Heidelberg and Berlin. This arrangement was successful and ECAP appeared with Steinkopff Publishers from volume 5 (1996) until volume 18 (2009). Since 2010 Springer Publishers 
have been the journal's Publisher. In 2005, Jan Buitelaar took over the position as editor-in-chief from Christopher Gillberg, and since January 2014, Johannes Hebebrand has been editor-in-chief. At its inception the journal was the official organ of ESCAP. However, during his term as president of ESCAP (2003-2007), Ernesto Caffo cut the links between ESCAP and ECAP arranging for a letter to be sent to the editors by a law firm saying that they were no longer allowed to state that the journal was the official organ of ESCAP. He argued that ESCAP had no control over the journal. He wanted to establish a new organisation, the "European Academy of Child and Adolescent Psychiatry" with its own journal.
After the ESCAP presidency had passed from Ernesto Caffo to Tuula Tamminen in 2008, an attempt was made to re-establish the lost links between ESCAP and ECAP and to make ECAP again "the official organ of ESCAP", a goal that was finally achieved in August 2011.

Nowadays, ECAP is the only peer-reviewed journal in Europe that is entirely devoted to child and adolescent psychiatry. It is a flourishing journal and currently publishing the 25th volume and has an impact factor of 3.339.

We wish the journal and all those who are working for it every success for the next 25 years. 